\title{
PARP inhibitors: the race is on
}

\author{
Jessica S Brown ${ }^{1,2}$, Stan B Kaye ${ }^{1,2}$ and Timothy A Yap ${ }^{\star, 1,2}$ \\ ${ }^{1}$ Drug Development Unit, Royal Marsden Hospital, London, UK and ${ }^{2}$ Division of Clinical Studies, The Institute of Cancer Research, \\ London, UK
}

Since the seminal publications in 2005 that demonstrated the exquisite sensitivity of $B R C A 1$ and BRCA2 (BRCA1/2) mutant cell lines and xenografts to poly(ADP-ribose) polymerase (PARP) inhibition (Bryant et al, 2005; Farmer et al, 2005), the race has been on to exploit single-agent PARP inhibitors for clinical use through the concept of tumour-specific synthetic lethality (Yap et al., 2011; O'Connor, 2015). In 2014, olaparib (Lynparza; AstraZeneca, London, UK) was the first PARP inhibitor to be approved by the European Medicines Agency as maintenance therapy for responding patients with $B R C A 1 / 2$ mutant ovarian cancer following platinum-based chemotherapy, and the first to obtain accelerated approval by the US Food and Drug Administration (FDA) for advanced BRCA1/2 mutant ovarian cancer while confirmatory trials are completed. There are, however, several other potent and bona fide PARP inhibitors, including rucaparib (AGO14699; Clovis, Boulder, CO, USA), niraparib (MK4827; Tesaro, Waltham, MA, USA), talazoparib (BMN-673; Medivation, San Francisco, CA,
USA) and veliparib (ABT-888; Abbvie, North Chicago, IL, USA), which are all currently in late phase clinical trial development (Table 1). Rucaparib was granted breakthrough therapy designation by the FDA in April 2015, following the results of the ARIEL2 trial (Kristeleit et al., 2015) for use as monotherapy in patients with BRCA1/2 mutant (germline or somatic) advanced ovarian cancer after at least two prior lines of platinum-containing therapy.

This publication by Drew et al. is the first study to report the tolerability and efficacy of rucaparib administered either through intravenous or oral routes, in patients with germline $B R C A 1 / 2$ mutant advanced breast or ovarian cancers. The study investigated different schedules and dose levels of rucaparib and included detailed pharmacodynamic (PD) and pharmacokinetic (PK) studies to assess relationships between PARP enzyme inhibition, drug PK and anti-tumour response. This study provides interesting insights and important lessons on the use of PARP inhibitors in this patient population, including

Table 1. Table showing the response rates and predominant toxicities for different PARP inhibitors in patients with advanced ovarian cancer

\begin{tabular}{|c|c|c|c|c|c|c|}
\hline \multicolumn{3}{|c|}{ BRCA1/2 mutant } & \multicolumn{2}{|c|}{$\begin{array}{c}\text { BRCA1/2 wild type and } \\
\text { unknown }\end{array}$} & \multirow[b]{2}{*}{$\begin{array}{l}\text { Predominant toxicity (in order } \\
\text { of frequency) }\end{array}$} & \multirow[b]{2}{*}{ References } \\
\hline Drug & No. & Response & No. & Response & & \\
\hline $\begin{array}{l}\text { Olaparib } \\
\text { (AZD2281) }\end{array}$ & $\begin{array}{l}>100 \text { (mostly } \\
\text { platinum resistant) }\end{array}$ & $30-60 \%$ & 46 & $\begin{array}{l}\text { Platinum sensitive } 50 \% \\
\text { Platinum resistant } 4 \%\end{array}$ & Gl symptoms, fatigue, anaemia & $\begin{array}{l}\text { (Fong et al, 2010; Gelmon et al, } \\
\text { 2011; Kaye et al, 2012) }\end{array}$ \\
\hline $\begin{array}{l}\text { Rucaparib } \\
\text { (AG014699) }\end{array}$ & $\begin{array}{l}39 \text { (all platinum } \\
\text { sensitive) }\end{array}$ & $69 \%$ & 132 & $\begin{array}{l}\mathrm{LOH}^{\text {high }} 29 \% \\
\mathrm{LOH}^{\text {low }} 13 \%\end{array}$ & $\begin{array}{l}\text { Gl symptoms, fatigue, anaemia, } \\
\text { transient ALT/AST elevations }\end{array}$ & (Kristeleit et al, 2015) \\
\hline $\begin{array}{l}\text { Niraparib } \\
\text { (MK4827) }\end{array}$ & $\begin{array}{l}20 \text { ( } 9 \text { platinum } \\
\text { sensitive) }\end{array}$ & $40 \%$ & $\begin{array}{l}3 \\
19\end{array}$ & $\begin{array}{l}\text { Platinum sensitive } 67 \% \\
\text { Platinum resistant } 16 \%\end{array}$ & $\begin{array}{l}\text { Anaemia, thrombocytopenia, } \\
\text { neutropenia, Gl symptoms, fatigue }\end{array}$ & (Sandhu et al, 2013) \\
\hline $\begin{array}{l}\text { Talazoparib } \\
\text { (BMN-673) }\end{array}$ & $26^{a}$ & $46 \%$ & - & - & $\begin{array}{l}\text { Fatigue, alopecia, GI symptoms, } \\
\text { anaemia, neutropenia, } \\
\text { thrombocytopenia }\end{array}$ & (Wainberg et al, 2014) \\
\hline $\begin{array}{l}\text { Veliparib } \\
\text { (ABT-888) }\end{array}$ & $28^{a, b}$ & $40 \%$ & $24^{a, b}$ & $4 \%$ & Nausea, fatigue, lymphopenia & (Puhalla et al, 2014) \\
\hline \multicolumn{7}{|c|}{$\begin{array}{l}\text { Abbreviations: } A L T=\text { alanine transaminase; } A S T=\text { aspartate transaminase; } \mathrm{Gl}=\text { gastrointestinal; } L O H=\text { loss of heterozygosity. } \\
\text { a }_{\text {Platinum responsiveness not known. }} \\
\text { b }_{\text {Includes triple negative breast cancer. }}\end{array}$} \\
\hline
\end{tabular}


the importance of continuous drug dosing, the challenges of PD biomarkers and the need for predictive biomarkers of response.

By quantifying the loss of poly(ADP-ribose) (PAR) chain formation in peripheral blood lymphocytes, Drew and colleagues demonstrate that PARP inhibition following rucaparib dosing is transient, recovering within 7 days. Coupled with the low response rate observed with the intermittent IV dosing of rucaparib, the authors provide strong rationale for continuous drug dosing. Interestingly, even in the continuous oral dosing cohort, response rates remained relatively low in this study at $18 \%$. This is likely to be because rucaparib dosing was still well below the recommended phase II dose of $600 \mathrm{mg}$ twice daily that was subsequently established. In addition, there was a high proportion of platinum-resistant patients included in this trial.

In general, reduction in PAR chain formation has been a useful PD biomarker to confirm target engagement for PARP inhibitors. Unsurprisingly, there is no correlation between this PD read-out and clinical anti-tumour activity for rucaparib (Drew et al., 2016), as previously observed with olaparib (Fong et al., 2009); near complete inhibition of PARP enzymatic activity was demonstrated even at subtherapeutic doses where there is no appreciable relationship between $\mathrm{PK}$ and $\mathrm{PD}$ studies. This discordance highlights an important point with regards to the mechanism of action of PARP inhibitors. PARP detects and localises to DNA single-strand breaks (SSBs) to facilitate SSB repair. Its activity then potentiates the recruitment of DNA SSB repair proteins to the chromatin and also promotes the dissociation of PARP itself from the DNA. PARP inhibition therefore traps PARP on the DNA at the sites of unrepaired SSBs, resulting in the generation of DNA double-strand breaks in S-phase that require homologous recombination for successful repair (Helleday, 2011; Murai et al., 2012). In keeping with this, at least in preclinical models, the most potent PARP inhibitors appear to be those that bind DNA most strongly; for example, talazoparib is $\sim 100$-fold more potent at trapping PARP-DNA complexes than rucaparib and olaparib (Shen et al., 2015). However, preclinical potency may not necessarily translate into clinical efficacy, as other factors such as drug-related toxicities limiting dose escalation and patient selection come into play. As discussed by Drew and co-workers, inter-assay variability makes the quantification and subsequent comparison of PARP activity between samples difficult. However, if PARP trapping is of clinical importance, it is possible that PARP expression or baseline PARP activity may be alternative or additional PD biomarkers for PARP inhibitors. Other biomarkers such as RAD51 and $\gamma \mathrm{H} 2 \mathrm{AX}$ should also be incorporated into early phase clinical trials to build confidence that robust PD activity was achieved.

A number of other critical questions remain in terms of optimising and widening the clinical efficacy and utility of PARP inhibitors, respectively. Although benefits are observed following PARP inhibitor treatment in patients with a range of tumour types with germline BRCA1/2 mutations (Kaufman et al., 2015), it is now clear that clinical efficacy is not restricted to this niche population of patients. A number of strategies have been explored to select patients who may benefit from PARP inhibitors, with the focus on the identification of predictive biomarkers for homologous recombination-deficient (HRD) tumours (Lord and Ashworth, 2016). Genomic approaches have included attempts to identify a molecular signature that predicts PARP inhibitor sensitivity (Konstantinopoulos et al., 2010), as well as the molecular characterisation of patients with castration-resistant prostate cancer for aberrations in multiple DNA repair genes (Mateo et al., 2015). Other approaches use one or a number of different genomic aberrations to determine HRD or an HRD score (Telli et al., 2015). More functional approaches have looked at ex vivo RAD51 foci formation in tumour cells before and after DNA- damaging treatment. The clinical development of rucaparib in high-grade serous ovarian cancer has included a loss of heterozygosity scoring system as a way of predicting response in patients with BRCA wild-type high-grade serous ovarian cancer. Preliminary data presented to date suggest that this may be a promising approach. In the ARIEL2 phase 2 study, a correlation between HRD score (high/low) and efficacy was noted, although interestingly the efficacy in HRD high patients still did not equate to patients with germline BRCA1/2 mutations (Table 1; Kristeleit et al., 2015). Thus, a robust predictive biomarker of PARP inhibitor sensitivity beyond $B R C A 1 / 2$ mutations has yet to be established prospectively in large clinical trials. Currently, prior sensitivity to cross-linking agents remains a useful clinical predictor of HRD and thus potential antitumour response to a PARP inhibitor (Fong et al., 2010). There are also preliminary data to suggest that the length of the time from the patient's last platinum chemotherapy will affect the sensitivity to PARP inhibitor treatment (Rafii et al., 2015).

To date, at least in an ovarian cancer population where PARP inhibitors have been most extensively studied, there appears to be little difference in the clinical effectiveness and toxicity profiles across the most advanced PARP inhibitors (Table 1), and the results of further large randomised trials with olaparib, rucaparib and niraparib are awaited with interest. It is interesting that relative to most other approved molecularly targeted agents, the clinical activity of single-agent PARP inhibitors in BRCA1/2 mutant tumours appears to be less context specific, although undoubtedly to date, high-grade serous ovarian cancers demonstrate the most impressive response rates, perhaps because of additional genomic aberrations that contribute to HRD. In order to become established in the clinic, it is likely that each of the PARP inhibitors will need to find their niche and area of unmet need. Being the first to demonstrate anti-tumour activity in a particular cancer type is oneway forward; other strategies may include successfully characterising a molecular subtype or a biomarker beyond germline BRCA1/2 mutant patients or defining a unique PARP inhibitor combination regimen. These include combinations of PARP inhibitors with inhibition of angiogenic, immune checkpoint, PI3K/AKT, WEE-1 and ATR pathways - all of which have the objective of tackling the key problem of PARP inhibitor resistance. In any event, the race is certainly now on with the availability of multiple potent PARP inhibitors, and such a wide and diverse range of new drug applications still open for exploration.

\section{REFERENCES}

Bryant HE, Schultz N, Thomas HD, Parker KM, Flower D, Lopez E, Kyle S, Meuth M, Curtin NJ, Helleday T (2005) Specific killing of BRCA2deficient tumours with inhibitors of poly(ADP-ribose) polymerase. Nature 434: 913-917.

Drew Y, Ledermann J, Hall G, Rea D, Glasspool R, Highley M, Jayson G, Sludden J, Murray J, Jamieson D, Halford S, Acton G, Backholer Z, Mangano R, Boddy A, Curtin N, Plummer R (2016) Phase 2 multicentre trial investigating intermittent and continuous dosing schedules of the poly(ADP-ribose) polymerase inhibitor rucaparib in germline BRCA mutation carriers with advanced ovarian and breast cancer. Br J Cancer. In press.

Farmer H, McCabe N, Lord CJ, Tutt ANJ, Johnson D a, Richardson TB, Santarosa M, Dillon KJ, Hickson I, Knights C, Martin NMB, Jackson SP, Smith GCM, Ashworth A (2005) Targeting the DNA repair defect in BRCA mutant cells as a therapeutic strategy. Nature 434: 917-921.

Fong PC, Boss DS, Yap TA, Tutt A, Wu P, Mergui-Roelvink M, Mortimer P, Swaisland H, Lau A, O'Connor MJ, Ashworth A, Carmichael J, Kaye SB, Schellens JHM, de Bono JS (2009) Inhibition of poly(ADP-ribose) polymerase in tumors from BRCA mutation carriers. N Engl J Med 361: 123-134.

Fong PC, Yap TA, Boss DS, Carden CP, Mergui-Roelvink M, Gourley C, De Greve J, Lubinski J, Shanley S, Messiou C, A'Hern R, Tutt A, Ashworth A, Stone J, Carmichael J, Schellens JHM, De Bono JS, Kaye SB (2010) 
Poly(ADP)-ribose polymerase inhibition: frequent durable responses in BRCA carrier ovarian cancer correlating with platinum-free interval. J Clin Oncol 28: 2512-2519.

Gelmon KA, Tischkowitz M, Mackay H, Swenerton K, Robidoux A, Tonkin K, Hirte H, Huntsman D, Clemons M, Gilks B, Yerushalmi R, Macpherson E, Carmichael J, Oza A (2011) Olaparib in patients with recurrent high-grade serous or poorly differentiated ovarian carcinoma or triple-negative breast cancer: a phase 2, multicentre, open-label, non-randomised study. Lancet Oncol 12: 852-861.

Helleday T (2011) The underlying mechanism for the PARP and BRCA synthetic lethality: clearing up the misunderstandings. Mol Oncol 5: 387-393.

Kaufman B, Shapira-Frommer R, Schmutzler RK, Audeh MW, Friedlander M, Balmana J, Mitchell G, Fried G, Stemmer SM, Hubert A, Rosengarten O, Steiner M, Loman N, Bowen K, Fielding A, Domchek SM (2015) Olaparib monotherapy in patients with advanced cancer and a germline BRCA1/2 mutation. J Clin Oncol 33: 244-250.

Kaye SB, Lubinski J, Matulonis U, Ang JE, Gourley C, Karlan BY, Amnon A, Bell-McGuinn KM, Chen LM, Friedlander M, Safra T, Vergote I, Wickens M, Lowe ES, Carmichael J, Kaufman B (2012) Phase II, open-label, randomized, multicenter study comparing the efficacy and safety of olaparib, a poly (ADP-ribose) polymerase inhibitor, and pegylated liposomal doxorubicin in patients with BRCA1 or BRCA2 mutations and recurrent ovarian cancer. J Clin Oncol 30: 372-379.

Konstantinopoulos PA, Spentzos D, Karlan BY, Taniguchi T, Fountzilas E, Francoeur N, Levine DA, Cannistra SA (2010) Gene expression profile of BRCAness that correlates with responsiveness to chemotherapy and with outcome in patients with epithelial ovarian cancer. J Clin Oncol 28: 3555-3561.

Kristeleit R, Swisher E, Oza A, Coleman R, Scott C, Konecny G, Tinker A, O’Malley D, Brenton J, Bell-McGuinn K, Oaknin A, Leary A, Lin K, Raponi M, Giordano H, Maloney L, Goble S, Yelensky R, McNeish I (2015) Final results of ARIEL2 (Part 1): a phase 2 trial to prospectively identify ovarian cancer $(\mathrm{OC})$ responders to rucaparib using tumor genetic analysis. Eur Cancer Congr 51: s531.

Lord CJ, Ashworth A (2016) BRCAness revisited. Nat Rev Cancer 16: 110-120.

Mateo J, Carreira S, Sandhu S, Miranda S, Mossop H, Perez-Lopez R, Nava Rodrigues D, Robinson D, Omlin A, Tunariu N, Boysen G, Porta N, Flohr P, Gillman A, Figueiredo I, Paulding C, Seed G, Jain S, Ralph C, Protheroe A, Hussain S, Jones R, Elliott T, McGovern U, Bianchini D, Goodall J, Zafeiriou Z, Williamson CT, Ferraldeschi R, Riisnaes R, Ebbs B, Fowler G, Roda D, Yuan W, Wu Y-M, Cao X, Brough R, Pemberton H, A'Hern R, Swain A, Kunju LP, Eeles R, Attard G, Lord CJ, Ashworth A, Rubin MA, Knudsen KE, Feng FY, Chinnaiyan AM, Hall E, de Bono JS (2015) DNA-repair defects and olaparib in metastatic prostate cancer. $N$ Engl J Med 373: $1697-1708$

Murai J, Huang SYN, Das BB, Renaud A, Zhang Y, Doroshow JH, Ji J, Takeda S, Pommier Y (2012) Trapping of PARP1 and PARP2 by clinical PARP inhibitors. Cancer Res 72: 5588-5599.

O'Connor MJ (2015) Targeting the DNA damage response in cancer. Mol Cell 60: $547-560$.
Puhalla S, Beumer JH, Pahuja S, Appleman LJ, Abdul-Hassan Tawbi H, Stoller RG, Lee JJ, Lin Y, Kiesel B, Yu J, Tan AR, Belani CP, Chew HK, Garcia AA, Morgan R, Giranda VL, Peacock Shepherd S, Chen AP, Chu E (2014) Final results of a phase 1 study of single-agent veliparib $(\mathrm{V})$ in patients (pts) with either BRCA1/2-mutated cancer (BRCA +), platinum-refractory ovarian, or basal-like breast cancer (BRCA-wt). 2014 ASCO Annual Meeting. Abstracts Meeting Library. Available at http://meetinglibrary.asco.org/content/129661144.

Rafii S, Gourley C, Ang JE, Kumar R, Geuna E, Rye T, Ashcroft L, Powell B, Shapira-Frommer R, Friedlander M, Chen L, Matulonis U, Kaufman B, De Greve J, Oza AM, Banerjee SN, Gore ME, Molife LR, Kaye SB, Yap TA (2015) What clinical factors influence advanced BRCA1/2 mutant ovarian cancer patient (BMOC pt) outcomes to poly(ADP-ribose) polymerase inhibitor (PARPi) treatment? 2015 ASCO Annual Meeting. Abstracts Meeting Library. Available at http://meetinglibrary.asco.org/content/ 149021-156.

Sandhu SK, Schelman WR, Wilding G, Moreno V, Baird RD, Miranda S, Hylands L, Riisnaes R, Forster M, Omlin A, Kreischer N, Thway K, Gevensleben H, Sun L, Loughney J, Chatterjee M, Toniatti C, Carpenter CL, Iannone R, Kaye SB, de Bono JS, Wenham RM (2013) The poly(ADPribose) polymerase inhibitor niraparib (MK4827) in BRCA mutation carriers and patients with sporadic cancer: A phase 1 dose-escalation trial. Lancet Oncol 14: 882-892.

Shen Y, Aoyagi-scharber M, Wang B (2015) Minireview Trapping Poly (ADP-Ribose) Polymerase. J Pharmacol Exp Ther 353(3): 446-457.

Telli ML, Timms K, Reid JE, Ford JM, Neff C, Abkevich V, Gutin A, Sangale Z, Illiev D, Jones JT, Hennessy B, Lanchbury JS, Mills GB, Hartman A-R, Ford JM (2015) Combined Homologous Recombination Deficiency (HRD) scores and response to neoadjuvant platinum-based chemotherapy in triplenegative and/or BRCA1/2 mutation-associated breast cancer. 2015 ASCO Annual Meeting. Abstracts Meeting Library. Available at http:// meetinglibrary.asco.org/content/150370-156.

Wainberg ZA, Rafii S, Ramanathan RK, Mina LA, Averett Byers L, Chugh R, Wade Goldman J, Sachdev JC, Matei DE, Wheler JJ, Henshaw JW, Zhang C, Gallant G, De Bono JS (2014) Safety and antitumor activity of the PARP inhibitor BMN673 in a phase 1 trial recruiting metastatic small-cell lung cancer (SCLC) and germline BRCA-mutation carrier cancer patients. 2014 ASCO Annual Meeting. Abstracts Meeting Library. Available at http://meetinglibrary.asco.org/content/128953-144.

Yap TA, Sandhu SK, Carden CP, de Bono JS (2011) Poly(ADP-ribose) polymerase (PARP) inhibitors: Exploiting a synthetic lethal strategy in the clinic. CA Cancer J Clin 61: 31-49.

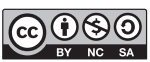

This work is licensed under the Creative Commons Attribution-Non-Commercial-Share Alike 4.0 International License. To view a copy of this license, visit http:// creativecommons.org/licenses/by-nc-sa/4.0/ 